\title{
Gait Pattern in People with Multiple Sclerosis: A Systematic Review
}

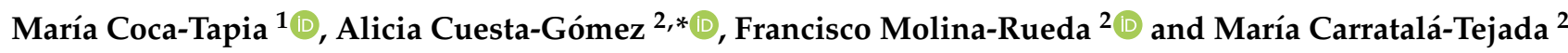 \\ 1 Masters School, Rey Juan Carlos University, 28933 Madrid, Spain; macocata12@gmail.com \\ 2 Motion Analysis, Ergonomics, Biomechanics and Motor Control Laboratory (LAMBECOM), \\ Department of Physical Therapy, Occupational Therapy, Rehabilitation and Physical Medicine, \\ Faculty of Health Sciences, Universidad Rey Juan Carlos, Alcorcón, 28922 Madrid, Spain; \\ francisco.molina@urjc.es (F.M.-R.); maria.carratala@urjc.es (M.C.-T.) \\ * Correspondence: alicia.cuesta@urjc.es; Tel.: +34-914-888-948
}

Citation: Coca-Tapia, M.;

Cuesta-Gómez, A.; Molina-Rueda, F.;

Carratalá-Tejada, M. Gait Pattern in

People with Multiple Sclerosis: A

Systematic Review. Diagnostics 2021,

11, 584. https://doi.org/10.3390/

diagnostics11040584

Academic Editor: Massimiliano

Calabrese

Received: 9 March 2021

Accepted: 22 March 2021

Published: 24 March 2021

Publisher's Note: MDPI stays neutral with regard to jurisdictional claims in published maps and institutional affiliations.

Copyright: (C) 2021 by the authors. Licensee MDPI, Basel, Switzerland. This article is an open access article distributed under the terms and conditions of the Creative Commons Attribution (CC BY) license (https:/ / creativecommons.org/licenses/by/ $4.0 /)$.

\begin{abstract}
The aim of the present systematic review was to describe the gait pattern in people with multiple sclerosis (MS) by compiling the main findings obtained from studies using threedimensional capture systems of human movement. The search was carried out in PubMed, Web of Science, Physiotherapy Evidence Database (PEDro), and the Cumulative Index to Nursing and Allied Health (CINAHL) databases. Studies that used three-dimensional gait analysis systems and that analyzed spatiotemporal, kinematic, kinetic, or electromyographic parameters, were included. The quality of the studies was assessed using the Critical Review Form-Quantitative Studies scale. 12 articles were included with 523 (342 women and $181 \mathrm{men}$ ) people with a diagnosis of MS. The present work suggests that people with MS have a decrease in speed and stride length, as well as an increase in double-stance intervals during gait. Likewise, it is common to observe a decrease in hip extension during the stance period, a decrease in knee flexion in the swing period, a decrease in ankle dorsiflexion in the initial contact and a decrease in ankle plantar flexion during the pre-swing phase. The subjects with MS decrease the hip extensor moment and the ankle power during the stance period of walking.
\end{abstract}

Keywords: multiple sclerosis; gait; biomechanics; three-dimensional motion capture systems

\section{Introduction}

Multiple sclerosis (MS) is a chronic, degenerative, and demyelinating disease, and one of the primary causes of disability in young adults in Europe and North America [1-5]. MS can cause sensory (40\%), pyramidal (40\%), cerebellar $(25 \%)$, and visual symptoms $(20 \%)[6,7]$. Gait deficiency is one of the main causes of disability in people with MS, and from the perspective of the patients it is the most challenging symptom [8-10]. In this sense, several authors have estimated that 15 years after the diagnosis of the disease, half of the patients will require assistance to walk and $10 \%$ will use a wheelchair $[11,12]$.

Gait abnormalities after a disorder of the central nervous system (CNS) are quite different, although it has been observed that some of the most common findings are a decrease in step length and single support time, slower speed, increase in step width, and decrease in ankle dorsiflexion angle and propulsive force $[13,14]$. In this sense, a typical gait pattern has not been described in MS unlike in other neurological disorders such as Parkinson's disease or stroke.

Various studies have described several abnormalities in the gait pattern of people with MS. Benedetti et al. showed a reduced speed of progression, shorter strides, and prolonged double support intervals in minimally impaired MS patients [15]. Preiningerova et al. observed that gait velocity decreases with increasing expanded disability status scale levels (EDSS) [16]. Despite these findings, walking abnormalities in MS patients are, nevertheless, poorly characterized. 
For gait assessment, a three-dimensional computerized analysis may be considered the criterion standard because it provides objective data on electromyography as well as kinetic and spatiotemporal parameters [1]. These tools assess the coordination of spatial and temporal aspects of the gait pattern.

As impaired gait coordination and recovery are of prime significance in neurorehabilitation, we conducted a systematic review to evaluate the gait abnormalities in people with MS registered though studies that used three-dimensional motion capture systems.

\section{Materials and Methods}

\subsection{Search Strategy}

The search was conducted from April to May 2020 using PubMed, Web of Science, Physiotherapy Evidence Database (PEDro), the Cumulative Index to Nursing and Allied Health, Web of Science, and the Cochrane Library. Only cross-sectional articles published in English, French, or Spanish were selected, without limits on the year of publication. The combinations of keywords used were as follows: ("Visual" OR "observational" OR "pattern") AND ("Gait" OR "ambulation" OR "walk") AND ("Assessment" OR "evaluation" OR “Test" OR "scale" OR "measure" OR “tool" OR “analysis" OR "profiling") AND "Multiple Sclerosis."

\subsection{Study Selection}

Studies that met the following inclusion criteria were included: (1) cross-sectional studies that use three-dimensional analysis to assess walking and evaluate the spatiotemporal, kinematic, kinetic, or electromyographic parameters; (2) the population under study is composed of adult patients with MS (aged $\geq 18 \mathrm{y}$ ). This systematic review excluded articles according to the following exclusion criteria: (1) studies that only use observational gait assessment scales; (2) studies that assess aspects of gait that are different from coordination of the gait pattern, such as walking resistance or level of walking impairment; studies without control group.

\subsection{Data Collection}

The general characteristics of the studies, including number of patients, type of MS, 3-dimensional motion capture system used, and biomechanical parameters examined, were extracted.

Two of the authors (F.M. and M.C.) conducted 2 independent assessments of the abstracts obtained from the electronic search. The reviewers decided which articles could potentially meet the inclusion criteria, and the works selected by each author were compared. Any disagreements were resolved after discussions with an independent third reviewer. For the studies that met the inclusion criteria, the full text articles were obtained.

\subsection{Methodological Quality}

The quality of the studies was assessed using the Critical Review Form-Quantitative Studies scale. This assessment tool assesses the rigor and bias of the method using a combination of dichotomous (yes/no) and descriptive elements. It incorporates 8 items, and each item is scored with 0 (does not meet the criteria) or 1 (meets the criteria). A higher score implies greater methodological quality of the evaluated study [17]. Finally, this review followed the PRISMA guidelines [18].

\section{Results}

\subsection{Description of the Studies}

Ninety-nine articles were found in the literature search. Once the abstracts were read, 17 of them were selected for further review and critical reading. Additionally, the references of these articles were reviewed to avoid loss of information that was not found in the bibliographic search, without obtaining any results. Finally, 5 articles were excluded in this review [19-23] and 12 were included [24-35] (Figure 1). 

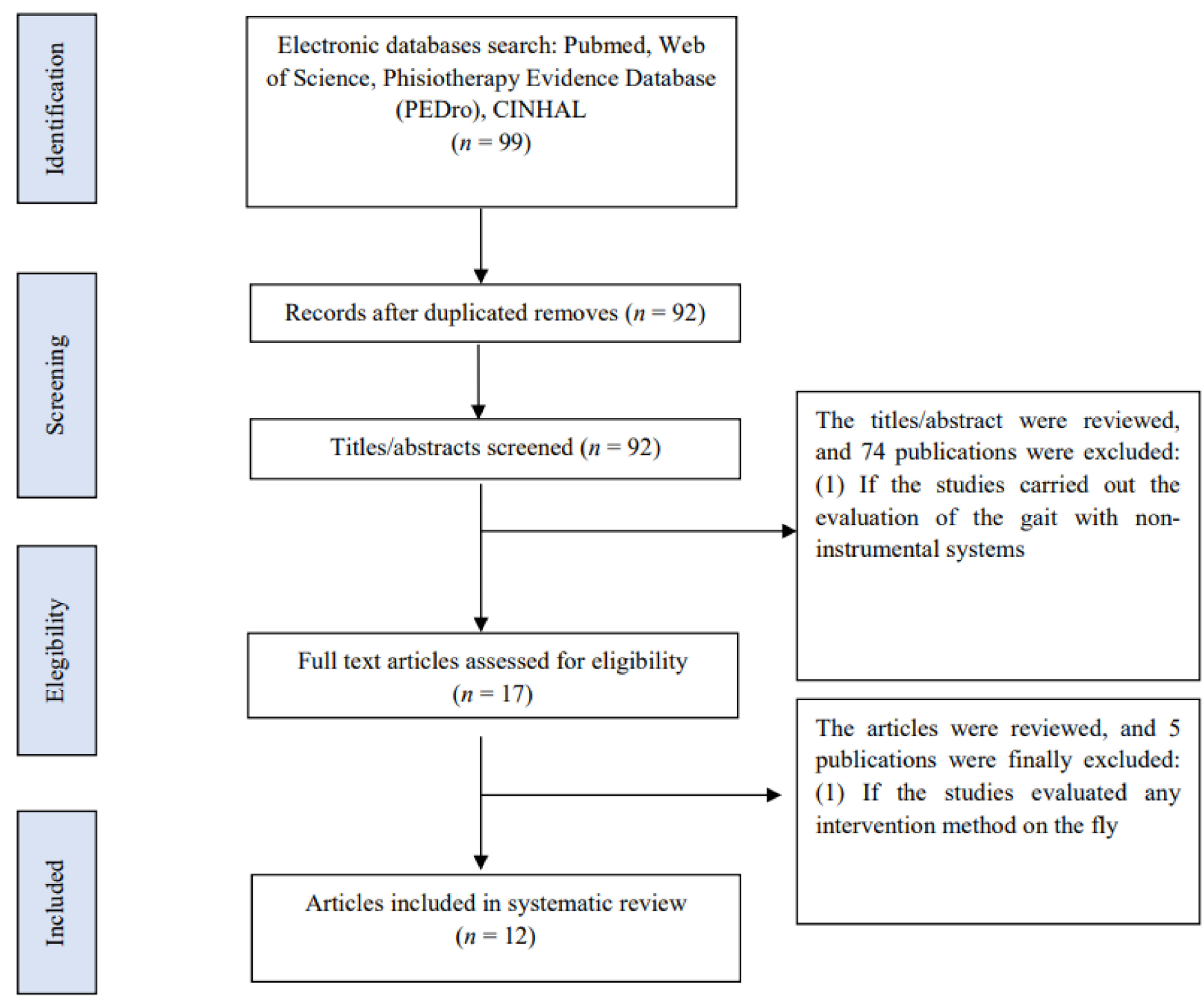

Figure 1. Flow chart.

All included studies enrolled 523 (342 women and 181 men) people with MS. Only three publications included the three types of MS: remitting recurrent (RR), progressive primary (PP), and progressive secondary (SP) $[24,25,27]$. In four studies, the authors only included RR-type MS [26,28,29,32] and two combinations of two types [33,34], and the remaining three did not specify what type of MS their participants had diagnosed $[30,31,35]$. All studies except one (which used the Hauser Index to classify participants as mild or moderately disabled) [34] classified the intervention subjects with the EDSS: two of them included participants with mild to moderate disability (EDSS $<4)[26,29]$, three included participants with moderate disability without aids in ambulation (EDSS $<5.5)[24,28,35]$, and the remaining six included users with mild to moderate disability with ambulation assistance using an assistive product (EDSS < 6.5) [25,27,30-33]. All studies except one [30] evaluated the spatiotemporal parameters of gait in MS, six included kinematic parameters [24-26,28,30,34], two included kinetic parameters [30,34], and two studies evaluated muscle activity during gait $[28,34]$ (Table 1 ). 
Table 1. Participant characteristics of the included articles.

\begin{tabular}{|c|c|c|c|c|c|c|c|c|}
\hline \multirow[b]{2}{*}{ Study } & \multicolumn{5}{|c|}{ Multiple Sclerosis Participants } & \multicolumn{3}{|c|}{ Control Participants } \\
\hline & $\mathbf{N}$ & $\begin{array}{c}\text { Sex } \\
(\mathrm{F}: \mathrm{M})\end{array}$ & Age & Type & EDSS & $\mathbf{N}$ & $\begin{array}{c}\text { Sex } \\
\text { (F:M) }\end{array}$ & Age \\
\hline Filli et al. 2018 [24] & 37 & $24: 13$ & 48.6 & $\begin{array}{c}22 \mathrm{RR} \\
2 \mathrm{PP} \\
13 \mathrm{SP}\end{array}$ & $1-4.5$ & 20 & $12: 8$ & 48.8 \\
\hline Severini et al. 2017 [25] & 51 & $30: 21$ & 51 & $\begin{array}{l}7 \mathrm{RR} \\
18 \mathrm{PP} \\
26 \mathrm{SP}\end{array}$ & $2-6.5$ & 10 & $2: 8$ & 36.7 \\
\hline Morel et al. 2017 [26] & 34 & $22: 12$ & 36.32 & $34 \mathrm{RR}$ & $\leq 2$ & 22 & $16: 6$ & 36.8 \\
\hline Remelius et al. 2015 [27] & 16 & $16: 0$ & 51.3 & $\begin{array}{c}15 \mathrm{RR} \\
2 \mathrm{PP} \\
2 \mathrm{SP}\end{array}$ & $2.5-6$ & 19 & 19:0 & 51.8 \\
\hline Pau et al. 2015 [28] & 19 & $12: 7$ & 54.6 & $19 \mathrm{RR}$ & $2.5-4.5$ & 19 & $7: 12$ & 47.1 \\
\hline Kalron et al. 2014 [29] & 20 & $8: 12$ & 36.3 & $20 \mathrm{RR}$ & $<4$ & 20 & $10: 10$ & 34.3 \\
\hline Huisinga et al. 2013 [30] & 31 & $26: 5$ & 46.2 & $\mathrm{NE}$ & $0-6.5$ & 31 & $23: 8$ & 42 \\
\hline Socie et al. 2013 [31] & 86 & $73: 13$ & 52.4 & $\mathrm{NE}$ & $2.5-6.5$ & 20 & $16: 4$ & 50.9 \\
\hline Kalron et al. 2013 [32] & 87 & $50: 37$ & 40.9 & $87 \mathrm{RR}$ & $<6$ & 25 & $14: 11$ & 38.5 \\
\hline Gianfrancesco et al. 2011 [33] & 11 & $7: 4$ & 53 & $\begin{array}{c}8 \mathrm{RR} \\
3 \mathrm{PP}\end{array}$ & $3.5-6$ & 13 & $6: 7$ & 47 \\
\hline Kelleher et al. 2010 [34] & 16 & $8: 8$ & 42.13 & $\begin{array}{l}\text { NE RR } \\
\text { NE SP }\end{array}$ & - & 10 & $5: 5$ & 37.2 \\
\hline Givon et al. 2009 [35] & 81 & $53: 28$ & 36.2 & $\mathrm{NE}$ & $\leq 5.5$ & 25 & $17: 8$ & 34.2 \\
\hline
\end{tabular}

N: number of participants; EDSS: expanded disability status scale; F: female; M: male; remitting recurrent MS (RR); progressive secondary MS (SP); progressive primary MS (PP); no specified (NE).

\subsection{Summary of the Results}

All the authors found significant differences in the spatiotemporal parameters, except one, which had a sample of MS users with minimal disability [26]. Most studies showed a decrease in gait speed and stride and step length [25,29,31-35]. Severini et al. [25] showed differences in gait speed according to the level of disability (low disability: $97.5 \mathrm{~cm} / \mathrm{s}$; moderate disability: $52 \mathrm{~cm} / \mathrm{s}$; severe disability: $23.9 \mathrm{~cm} / \mathrm{s}$ vs. control: $139.2 \mathrm{~cm} / \mathrm{s}$ ). Remilius et al. [27] reported a decrease in the swing period duration during walking in MS patients (MS: $230 \mathrm{~mm}$ vs. control $253 \mathrm{~mm}$ ) while Pau et al. [28] expressed an increase in the percentage of the stance period (MS: 65.48-67.75\% vs. control: 61.79-61.32\%). Two studies [31,32] found an increase in the step width (Socie et al.: MS: $12.6 \mathrm{~cm}$ vs. control $8.6 \mathrm{~cm}$; Kalron et al.: MS: $13.8 \mathrm{~cm}$ vs. control: $11.0 \mathrm{~cm}$ ).

Regarding the kinematic parameters, two studies recorded data from the pelvis. Severini et al. [25] found an increase in pelvic tilt and hiking throughout the gait cycle. Morel et al. [26] observed a reduced pelvis tilt and obliquity during walking in MS patients with EDSS $\leq 2$.

At the hip joint, the studies described a decrease in the maximum extension in the stance period in patients with mild to moderate involvement (EDSS $\leq 6.5$ ) (moderate disability: $-5.5^{\circ}$, high disability: $1.4^{\circ}$ vs. control: $-12.50^{\circ}$ ) [25]. However, in patients with less involvement (EDSS $<4)$, the studies did not suggest significant differences in the hip pattern [29].

Regarding the knee joint, publications described a decrease in the maximum flexion achieved during the swing period [24,25] (Filli et al.: MS: $35^{\circ}$ vs. control 55 $5^{\circ}$ Severini et al.: low disability: $42.2^{\circ}$, moderate disability: $30.6^{\circ}$; severe disability: $14.2^{\circ}$ vs. control: $57.0^{\circ}$ ). At the ankle joint, several studies observed a decreased dorsiflexion during the stance [24,25,30] (Filli et al.: MS: $-10^{\circ}$ vs. control: $-5^{\circ}$; MS: $-10^{\circ}$ vs. control: $0^{\circ}$; Severini et al.: severe disability: $5^{\circ}$ vs. control: $12^{\circ}$ ), and a decreased plantar flexion in the pre-swing phase [26,30] (Morel at al.: MS: $-14.67^{\circ}$ vs. control: $-20.0^{\circ}$ ) (Table 2 ). 
Table 2. Synthesis of the results.

\section{Study}

Kinematic

Kinetic

Vicon Motion System ${ }^{\circledR}$

Gait System Used

Decrease in speed (MS: $6.2 \mathrm{~s}$ vs. Control: $3.6 \mathrm{~s} ; p<0.0001)$.

Kinematics: decreased knee flexion during swing phase (MS: $35^{\circ}$ vs. control $55^{\circ}$; $p<0.05)$ and decreased ankle dorsiflexion during the initial contact and swing period (MS: $-10^{\circ}$ vs. control: $-5^{\circ}$; MS: $-10^{\circ}$ vs. control: $0^{\circ} ; \mathrm{p}<0.05$ ).

Follow-up after one year: greater deterioration in gait of the spastic-paretic type $(p=0.0473)$ and greater deterioration in knee parameters $(p=0.0129)$.

Differences in spatiotemporal parameters according to the degree of MS disability decrease in speed (low disability: $97.5 \mathrm{~cm} / \mathrm{s}$; moderate disability: $52 \mathrm{~cm} / \mathrm{s}$; severe disability: $23.9 \mathrm{~cm} / \mathrm{s}$ vs. control: $139.2 \mathrm{~cm} / \mathrm{s} ; p<0.001$ ).

Stride length decreased (low disability: $111.9 \mathrm{~cm}$; moderate disability: $82.6 \mathrm{~cm}$; severe disability: $55.8 \mathrm{~cm}$ vs. control: $139.2 \mathrm{~cm} ; p<0.001$ ).
Spatiotemporal parameters Kinematic
Vicon Motion System ${ }^{\circledR}$

severe disability: $55.8 \mathrm{~cm}$ vs. control: $139.2 \mathrm{~cm} ; p<0.001)$.
Pelvis: increased pelvic tilt and hiking. Hip Kinematic: decreased extension during pre-swing (moderate disability: $-5.5^{\circ}$, high disability: $1.4^{\circ}$ vs. control: $-12.50^{\circ}$. $p<0.0001$ ); knee: decreased flexion during swing period (low disability: $42.2^{\circ}$, moderate disability: $30.6^{\circ}$; severe disability: $14.2^{\circ}$ vs. control: $57.0^{\circ} ; p<0.0005$ ); ankle: decreased dorsiflexion during stance period (severe disability: $5^{\circ}$ vs. control:

$$
\left.12^{\circ} ; p=0.01\right)
$$

Pelvis Kinematic: decreased pelvis tilt (MS: $9.09^{\circ}$ vs. control: $11.08^{\circ} ; p=0.033$ ) and reduced obliquity range (MS: $10.33^{\circ}$ vs. control: $\left.12.83^{\circ}, p<0.001\right)$. Ankle: increased dorsiflexion during mid-stance and decreased plantar flexion in pre-swing (MS: $-14.67^{\circ}$ vs. control: $\left.-20.0^{\circ} p<0.001\right)$.
Vicon Motion System ${ }^{\circledR}$
Duration of the swing period is decreased (MS: $385 \mathrm{~ms}$ vs. control: $401 \mathrm{~ms}$; $p=0.004)$.

Anteriorized COM in the swing perio
Decrease in speed (MS: $0.42 \mathrm{~m} / \mathrm{s}$ vs. control: $1.12 \mathrm{~m} / \mathrm{s} ; p<0.001$ ) and increase in the percentage of the stance period (MS: $65.48-67.75 \%$ vs. control: $61.79-61.32 \%$; $p=0.021)$.

Pau et al. $2015[28$
Spatiotemporal parameters Kinematic

Electromyography
Smart-D System ncrease in the rectus femoris activation throughout the gait cycle (RMS in MS: $0.644-0.639 \mathrm{~W} / \mathrm{s}$ vs. control: $0.504-0.493 \mathrm{~W} / \mathrm{s} ; p<0.001$ ). 
Table 2. Cont.

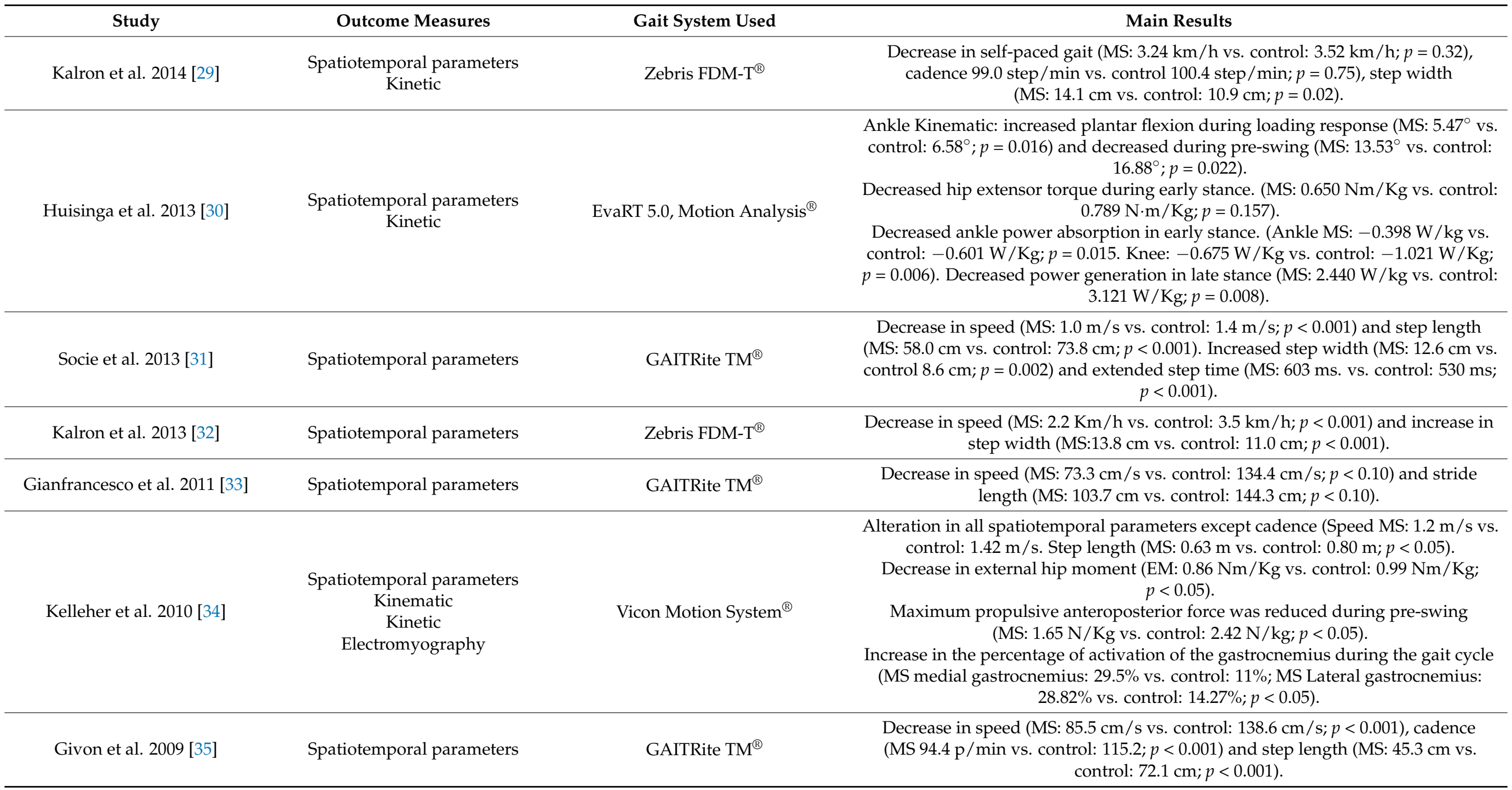

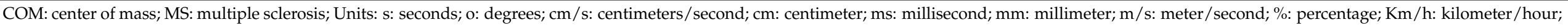

mm2: square millimeter; Nm/Kg: newton-meter/kilogram; W/Kg: watt/kilogram (power); p/s: step/second. 
The kinetic characteristics are described in two publications [30,34]. Huisinga et al. [30] and Kelleher et al. [34] analyzed the joint internal moments. Both authors observed a decrease in the hip extensor moment (Huisinga et al.: MS: $0.650 \mathrm{Nm} / \mathrm{Kg}$ vs. control: $0.789 \mathrm{Nm} / \mathrm{Kg}$; Kelleher et al.: EM: $0.86 \mathrm{Nm} / \mathrm{Kg}$ vs. control: $0.99 \mathrm{Nm} / \mathrm{Kg}$ ) during the mid-stance phase. In addition, Huisinga et al. [30] registered a decrease in the ankle power generated (MS: $2.440 \mathrm{~W} / \mathrm{kg}$ vs. control: $3.121 \mathrm{~W} / \mathrm{Kg}$ ).

The electromyographic characteristics of the gait pattern were only evaluated in two studies. Pau et al. [28] described an increase in rectus femoris activation throughout the gait cycle in individuals with spasticity, while Kelleher et al. [34] found an increase in the percentage of activation of the plantar flexor muscles during the stance period.

\subsection{Methodological Quality}

The methodological quality of the included studies is detailed in Table 3. The scores obtained range from $11[25,28]$ to a maximum of 15 [24]. All studies reflect the research purpose and the design of the protocol. The sample is well described in all studies, but only two works justified the sample size [24,33], which increases the probability of the appearance of selection bias.

Table 3. Methodological quality of the included articles.

\begin{tabular}{ccccccccccccccccc}
\hline ITEMS & $\mathbf{1}$ & $\mathbf{2}$ & $\mathbf{3}$ & $\mathbf{4}$ & $\mathbf{5}$ & $\mathbf{6}$ & $\mathbf{7}$ & $\mathbf{8}$ & $\mathbf{9}$ & $\mathbf{1 0}$ & $\mathbf{1 1}$ & $\mathbf{1 2}$ & $\mathbf{1 3}$ & $\mathbf{1 4}$ & $\mathbf{1 5}$ & TOTAL \\
\hline Filli et al. 2018 [24] & 1 & 1 & 1 & 1 & 1 & 1 & 1 & 1 & 1 & 1 & 1 & 1 & 1 & 1 & 1 & 15 \\
Severini et al. 2017 [25] & 1 & 1 & 1 & 1 & 0 & 1 & 1 & 1 & 1 & 1 & 1 & 0 & 0 & 0 & 1 & 11 \\
Morel et al. 2017 [26] & 1 & 1 & 1 & 1 & 0 & 1 & 1 & 1 & 1 & 1 & 1 & 1 & 0 & 0 & 1 & 12 \\
Remelius et al. 2015 [27] & 1 & 1 & 1 & 1 & 0 & 1 & 1 & 1 & 1 & 1 & 1 & 1 & 0 & 0 & 1 & 12 \\
Pau et al. 2015 [28] & 1 & 1 & 1 & 1 & 0 & 1 & 1 & 1 & 1 & 1 & 1 & 0 & 0 & 0 & 1 & 11 \\
Kalron et al. 2014 [29] & 1 & 1 & 1 & 1 & 1 & 1 & 1 & 1 & 1 & 1 & 1 & 0 & 0 & 0 & 1 & 12 \\
Huisinga et al. 2013 [30] & 1 & 1 & 1 & 1 & 0 & 1 & 1 & 1 & 1 & 1 & 1 & 1 & 0 & 0 & 1 & 12 \\
Socie et al. 2013 [31] & 1 & 1 & 1 & 1 & 0 & 1 & 1 & 1 & 1 & 1 & 1 & 1 & 0 & 0 & 1 & 12 \\
Kalron et al. 2013 [32] & 1 & 1 & 1 & 1 & 0 & 1 & 1 & 1 & 1 & 1 & 1 & 1 & 1 & 0 & 1 & 13 \\
Gianfrancesco et al. 2011 [33] & 1 & 1 & 1 & 1 & 1 & 1 & 1 & 1 & 1 & 1 & 1 & 1 & 0 & 0 & 1 & 13 \\
Kelleher et al. 2010 [34] & 1 & 1 & 1 & 1 & 0 & 1 & 1 & 1 & 1 & 1 & 1 & 1 & 0 & 0 & 1 & 12 \\
Givon et al. 2009 [35] & 1 & 1 & 1 & 1 & 1 & 1 & 1 & 1 & 1 & 1 & 1 & 1 & 0 & 0 & 1 & 13 \\
\hline
\end{tabular}

Items: 1 . study purpose; 2 . literature; 3 . design; 4 . sample described; 5 . sample size justified; 6 . outcome measures reliable; 7 . outcome measures valid; 8 . description of the intervention; 9 . contamination; 10 . cointervention; 11. statistical significance of the results; 12 . analysis method(s); 13. clinical importance; 14. dropouts; 15. conclusions.

\section{Discussion}

The gait pattern in people with MS depends on the location of the injuries and the degree of damage. For these reasons, it is difficult to homogenize the gait abnormalities and stablish a standardized atypical pattern. All the studies included in this review have reported involvement of the spatiotemporal parameters of the gait, specifically a decrease in the speed and stride and step length.

Regarding the kinematic and kinetic parameters, those with MS walk with a reduced hip extension and hip extension moment in the stance period $[25,30,34]$. This pattern could be explained by an increase in the quadricep tone in patients with spasticity or by a weakness of the hip extensor muscles. The weakness of the hip extensor musculature could explain the reduction in hip extensor moment described by several articles during the stance period $[25,34]$. The restriction of hip extension is correlated with a higher risk of falls in people with neurological pathology [36] and in elderly people [37,38].

At the knee joint, there is some consensus that people with MS reduce the flexion during the swing period $[24,25,28,34]$. Some authors also observed an increase in knee flexion in the loading response [34]. Therefore, impaired knee flexion could be one of the main kinematic features of MS gait [24]. This is congruent with previous studies reporting that impaired knee flexion is an important MS-associated gait characteristic and a valid predictor of walking function/gait speed in these patients [24,39]. The reduced knee flexion during the swing phase may be caused by paresis (e.g., hamstrings), increase 
in muscle tone (e.g., rectus femoris) or decreased push-of power in the ankle joint (e.g., gastrocnemius) [24,40].

Regarding the ankle joint, the main alteration described is the decreased dorsiflexion during the stance and the restricted plantar flexion during the toe off $[24-26,30]$. These findings could be related to an increase in the plantar flexor muscles tone during the stance period in subjects with spasticity [30]. This pattern is congruent with the kinetics recorded in two of the studies, which report a decrease in the power generated in the pre-swing phase [30]. The ankle power, which is the amount of power (energy) transmitted through the action of forces generated by the musculotendinous structures, is considered a good predictor of the impairment of stride length in elderly people and is positively correlated with stride length and speed [41].

The restriction of motion at hip, knee and ankle could cause an increase in the pelvic tilt and hiking during walking, as reported Severini et al. [25]. However, this pelvis pattern has not been observed in those with MS with mild disability [26]. Therefore, the pelvic pattern could be affected by disease progression and as compensation for restricted movement in the hip, knee, or ankle joints during walking.

These alterations observed in the kinematic pattern of subjects with MS should be considered in the evaluation process, since this asymmetrical pattern demonstrates the gait deterioration throughout the course of the disease. Rehabilitation should prevent asymmetries such as decreased hip extension or knee flexion during walking, as these are findings that indicate deterioration or progression of the disease. Several authors have demonstrated that rehabilitation improves walking in people with MS. Tramonti et al. [42] showed that an intensive task-oriented circuit training improved fatigue, perceived ambulatory function and knee force in mildly impaired MS subjects. Benito-Villalvilla et al. [43], in a systematic review, expressed that motor imagery and its combination with relaxation techniques improve fatigue, gait, balance, depression and quality of life in people with MS. In addition, Robinson et al. [44] showed that treadmill training may be an effective form of task-specific training for improving walking in people with MS.

The gait described in this review could be greater in MS patients with spasticity-related signs. They present a greater reduction in speed and higher increase in the percentage double support periods. On the other hand, the main gait characteristics in MS patients with cerebellar involvement are an increase in the step width [31,32]. This is congruent with other works which show a more asymmetric gait pattern in MS patients with spasticityrelated signs compared to the those with cerebellar involvement $[45,46]$. There are also other publications that have compared the risk of falls in both groups, and there does not seem to be conclusive data on this [47-50]. These studies reported the possibility of falling is mainly correlated with the level of disability and the presence of visual impairment.

Regarding the EDSS levels, one of the studies carried out with patients with mild disability (EDSS $\leq 2$ ) did not find significant differences with respect to the control group [26]. Another study [25], which divided the participants into mild, moderate, and severe disability, did find an impairment of speed and stride length in the mild group. The rest of the studies had participants with moderate disabilities, and although they show that the parameters increase their asymmetry with the progression of the disease, they do not specify in which EDSS score it occurs. This could suggest that the gait pattern alterations do not appear in the earliest phase of the disease and that they tend to worsen as the disease progresses.

This review has some limitations that should be highlighted. First, only papers in English, Spanish or French were considered, so there may be works that have not been studied. Second, some of the articles included have small samples, the years of evolution of the disease fluctuate, and the data collection systems are different, which contributes heterogeneity to the results described. Third, this review cannot draw conclusions about differences in gait pattern according to several clinical variables that have not been considered in most of the included studies (i.e., numbers of clinical relapses in patients with RR-MS; site of demyelinating lesions) In addition, this review considered articles that report the 
MS clinical phenotype, but they did not establish comparisons between gait abnormalities pattern and MS phenotype. In addition, there are three articles that did not report the MS clinical phenotype. Further research on these comparisons should be considered.

\section{Conclusions}

The present review suggests that people with MS have a decrease in speed and stride and step length and an increase in the step width. It is common to observe a decrease in hip extension during the stance period, a decrease in knee flexion in the swing period, a decrease in ankle dorsiflexion in the initial contact and a decrease in ankle plantar flexion during the pre-swing phase. The subjects with MS walk with a decreased hip extensor moment and ankle power.

Regarding to the gait pattern in different MS subgroups, it seems that walking is worse in patients with spasticity-related signs compared to those with cerebellar signs. All these parameters appear to worsen as the EDSS score progresses and are not seen in mildly disabled individuals. These results may help to improve rehabilitative gait training in MS patients and to develop specific exercise programs. Furthermore, these findings are relevant for future research to compare the gait pattern in patients with different types of multiple sclerosis.

Author Contributions: Conceptualization, M.C.-T. (María Coca-Tapia) and F.M.-R.; investigation, M.C.-T. (María Coca-Tapia), F.M.-R., and A.C.-G.; writing-review and editing, M.C.-T. (María CocaTapia), F.M.-R., A.C.-G. and M.C.-T. (María Carratalá-Tejada); supervision, F.M.-R. All authors have read and agreed to the published version of the manuscript.

Funding: This research received no external funding.

Conflicts of Interest: The authors declare no conflict of interest.

\section{References}

1. Gor-García-Fogeda, M.D.; Tomé-Redondo, S.; Simón-Hidalgo, C.; Daly, J.J.; Molina-Rueda, F.; Cano-de-la-Cuerda, R. Reliability and Minimal Detectable Change in the Gait Assessment and Intervention Tool in Patients with Multiple Sclerosis. PMR 2020, 12, 685-691. [CrossRef] [PubMed]

2. Merino, A.G.; Callizo, J.R.A.; Fernández, O.F.; Pascual, L.L.; Torres, E.M.; Zarrantz, A.R.-A. Consensus statement on the treatment of multiple sclerosis by the Spanish Society of Neurology in 2016. Neurología 2017, 32, 113-119.

3. Otero-Romero, S.; Batlle, J.; Bonaventura, I.; Brieva, L.L.; Bufill, E.; Cano, A.; Carmona, O.; Escartín, A.; Marco, M.; Moral, E.; et al. Situación epidemiológica actual de la esclerosis múltiple: Pertinencia y puesta en marcha de un registro poblacional de nuevos casos en Cataluña. Neurologia 2010, 50, 623-626. [CrossRef]

4. Poser, C.M.; Brinar, V.V. The accuracy of prevalence rates of multiple sclerosis: A critical review. Neuroepidemiology 2007, 29, 150-155. [CrossRef] [PubMed]

5. Instituto Nacional de Estadística. Encuesta Sobre Discapacidades, Autonomía Personal y Situaciones de Dependencia: EDAD 2008; INE: Madrid, Spain, 2008.

6. Carretero Ares, J.L.; BowakimDib, W.; Acebes Rey, J.M. Neurología y Medicina Interna Actualización: Esclerosis múltiple. Medifam 2001, 11, 516-529. [CrossRef]

7. Fernández, O.; Fernández, V.E.; Guerrero, M. Esclerosis Múltiple. Med. Programa Form. Médica Contin. Acreditado 2015, 11, 4610-4621. [CrossRef]

8. Heesen, C.; Böhm, J.; Reich, C.; Kasper, J.; Goebel, M.; Gold, S.M. Patient perception of bodily functions in multiple sclerosis: Gait and visual function are the most valuable. Mult. Scler. 2008, 14, 988-991. [CrossRef]

9. Larocca, N.G. Impact of walking impairment in multiple sclerosis: Perspectives of patients and care partners. Patient 2011, 4, 189-201. [CrossRef]

10. Dalgas, U. Rehabilitation and multiple sclerosis: Hot topics in the preservation of physical functioning. Neurol. Sci. 2011, 311, 43-47. [CrossRef]

11. Noseworthy, J.H.; Lucchinetti, C.; Rodriguez, M.; Weinshenker, B.G. Medical progress: Multiple sclerosis. N. Engl. J. Med. 2000, 343, 938-952. [CrossRef]

12. Assmann, K.; Winant, D.N.; Seidle, M.; Carter, A. Gait characteristics in multiple sclerosis: Progressive changes and effects of exercise on parameters. Arch. Phys. Med. Rehabil. 1986, 67, 536-539.

13. Gor-García-Fogeda, M.D.; Cano de la Cuerda, R.; Carratalá Tejada, M.; Alguacil-Diego, I.M.; Molina-Rueda, F. Observational Gait Assessments in People with Neurological Disorders: A Systematic Review. Arch. Phys. Med. Rehabil. 2016, 97, 131-140. [CrossRef] [PubMed] 
14. Crenshaw, S.J.; Royer, T.D.; Richards, J.G.; Hudson, D.J. Gait variability in people with multiple sclerosis. Mult. Scler. 2006, 12, 613-619. [CrossRef] [PubMed]

15. Benedetti, M.G.; Riperno, R.; Simoncini, L.; Bonato, P.; Tonini, A.; Giannini, S. Gait abnormalities in minimally impaired multiple sclerosis patients. Mult. Scler. 1999, 5, 363-368. [CrossRef]

16. Preiningerova, J.L.; Novotna, K.; Rusz, J.; Sucha, L.; Ruzicka, E.; Havrdova, E. Spatial and temporal characteristics of gait as outcome measures in multiple sclerosis (EDSS 0 to 6.5). J. Neuroeng. Rehabil. 2015, 12, 14. [CrossRef] [PubMed]

17. Law, M.; Stewart, D.; Pollicj, N.; Letts, L.; Bosch, J.; Westmorland, M. Guidelines for Critical Review Form-Quantitative Studies; McMaster University: Hamilton, ON, Canada, 1998.

18. Hutton, B.; Catalá López, F.; Moher, D. The PRISMA statement extensión for systematic reviews incorporating network metaanalysis: PRISMA-NMA. Med. Clin. 2016, 147, 262-266. [CrossRef]

19. Liparoti, M.; Della Corte, M.; Ruccoa, R.; Sorrentinod, R.; Sparacob, M.; Capuanob, R.; Minino, R.; Lavorgna, L.; Agosti, V.; Sorrentino, G.; et al. Gait abnormalities in minimally disabled people with Multiple Sclerosis: A 3D-motion analysis study. Mult. Scler. Relat. Disord. 2019, 29, 100-107. [CrossRef] [PubMed]

20. Kalron, A. Association between perceived fatigue and gait parameters measured by an instrumented treadmill in people with multiple sclerosis: A cross-sectional study. J. Neuroeng. Rehabil. 2015, 12, 34. [CrossRef]

21. Mañago, M.M.; Hebert, J.R.; Kittelson, J.; Schenkman, M. Contributions of Ankle, Knee, Hip, and Trunk Muscle Function to Gait Performance in People with Multiple Sclerosis: A Cross-Sectional Analysis. Phys. Ther. 2018, 98, 595-604. [CrossRef]

22. Cofré Lizama, L.E.; Khan, F.; Vs Lee, P.; Galea, M.P. The use of laboratory gait analysis for understanding gait deterioration in people with multiple sclerosis. Mult. Scler. 2016, 14, 1768-1776. [CrossRef]

23. Van der Linden, M.L.; Scott, S.M.; Hooper, J.E.; Cowan, P.; Mercer, T.H. Gait kinematics of people with Multiple Sclerosis and the acute application of Functional Electrical Stimulation. Gait Posture 2014, 39, 1092-1096. [CrossRef]

24. Filli, L.; Sutter, T.; Easthope, C.S.; Killeen, T.; Meyer, C.; Reuter, K.; Lörincz, L.; Bolliger, M.; Weller, M.; Curt, A.; et al. Profiling walking dysfunction in multiple sclerosis: Characterisation, classification and progression over time. Sci. Rep. 2018, 8, 1-13. [CrossRef] [PubMed]

25. Severini, G.; Manca, M.; Ferraresi, G.; Caniatti, L.M.; Cosma, M.; Baldasso, F.; Straudi, S.; Morelli, M.; Basaglia, N. Evaluation of Clinical Gait Analysis parameters in patients affected by Multiple Sclerosis: Analysis of kinematics. Clin. Biomech. 2017, 45, 1-8. [CrossRef] [PubMed]

26. Morel, E.; Allali, G.; Laidet, M.; Assal, F.; Lalive, P.H.; Armand, S. Gait profile score in multiple sclerosis patients with low disability. Gait Posture 2017, 51, 169-173. [CrossRef]

27. Remelius, J.G.; van Emmerik, R.E. Time-to-contact analysis of gait stability in the swing phase of walking in people with multiple sclerosis. Motor Control 2015, 19, 289-311. [CrossRef] [PubMed]

28. Pau, M.; Coghe, G.; Corona, F.; Giovanna Marrosu, M.; Cocco, E. Effect of spasticity on kinematics of gait and muscular activation in people with multiple sclerosis. J. Neurol. Sci. 2015, 358, 339-344. [CrossRef]

29. Kalron, A.; Dvir, Z.; Givon, U.; Baransi, H.; Achiron, A. Gait and jogging parameters in people with minimally impaired multiple sclerosis. Gait Posture 2014, 39, 297-302. [CrossRef]

30. Huisinga, J.M.; Schmid, K.K.; Filipi, M.L.; Stergiou, N. Gait mechanics are different between healthy controls and patients with multiple sclerosis. J. Appl. Biomech. 2012, 29, 303-311. [CrossRef] [PubMed]

31. Socie, M.J.; Motl, R.W.; Pula, J.H.; Sandroff, B.M.; Sosnoff, J.J. Gait variability and disability in multiple sclerosis. Gait Posture 2012, 38, 51-55. [CrossRef] [PubMed]

32. Kalron, A.; Dvir, Z.; Frid, L.; Achiron, A. Quantifying gait impairment using an instrumented treadmill in people with multiple sclerosis. ISRN Neurol. 2013, 2013, 867575. [CrossRef]

33. Gianfrancesco, M.A.; Triche, E.W.; Fawcett, J.A.; Labas, M.P.; Patterson, T.S.; Lo, A.C. Speed- and cane-related alterations in gait parameters in individuals with multiple sclerosis. Gait Posture 2011, 33, 140-142. [CrossRef]

34. Kelleher, K.J.; Spence, W.; Solomonidis, S.; Apatsidis, D. The characterisation of gait patterns of people with multiple sclerosis. Disabil. Rehabil. 2010, 32, 1242-1250. [CrossRef]

35. Givon, U.; Zeilig, G.; Achiron, A. Gait analysis in multiple sclerosis: Characterization of temporal-spatial parameters using GAITRite functional ambulation system. Gait Posture 2009, 29, 138-142. [CrossRef]

36. Fernández-González, P.; Molina-Rueda, F.; Cuesta-Gomez, A.; Carratalá-Tejada, M.; Miangolarra-Page, J.C. Instrumental gait analysis in stroke patients. Rev. Neurol. 2016, 63, 433-439. [PubMed]

37. Casey Kerrigan, D.; Lee, L.W.; Collins, J.J.; Riley, P.O.; Lipsitz, L.A. Reduced Hip Extension During Walking: Healthy Elderly and Fallers Versus Young Adults. Arch. Phys. Med. Rehabil. 2001, 82, 26-30. [CrossRef]

38. Grabiner, P.; Biswas, T.; Grabiner, M. Age-Related changes in spatial and temporal gait variables. Arch. Phys. Med. Rehabil. 2001, 82, 31-35. [CrossRef] [PubMed]

39. Broekmans, T.; Gijbels, D.; Eijnde, B.O.; Alders, G.; Lamers, I.; Roelants, M.; Feys, P. The relationship between upper leg muscle strength and walking capacity in persons with multiple sclerosis. Mult. Scler. 2013, 19, 112-119. [CrossRef] [PubMed]

40. Campanini, I.; Merlo, A.; Damiano, B. A method to differentiate the causes of stiff-knee gait in stroke patients. Gait Posture 2013, 38, 165-169. [CrossRef]

41. Rueda, F.M.; Tejada, M.C. Patrón cinético y electromiográfico de la marcha. In Biomecánica, Evaluación y Patología, 1st ed.; Tejada, M.C., Rueda, F.M., Eds.; La Marcha Humana; Panamericana: Madrid, Spain, 2020; pp. 36-37. 
42. Tramonti, C.; Di Martino, S.; Chisari, C. An intensive task-oriented circuit training positively impacts gait biomechanics in MS patients. NeuroRehabilitation 2020, 46, 321-331. [CrossRef] [PubMed]

43. Benito-Villalvilla, D.; de Uralde-Villanueva, I.L.; Ríos-León, M.; Álvarez-Melcón, A.C.; Martín-Casas, P. Effectiveness of motor imagery in patients with multiple sclerosis: A systematic review. Rev. Neurol. 2021, 72, 157-167.

44. Robinson, A.G.; Dennett, A.M.; Snowdon, D.A. Treadmill training may be an effective form of task-specific training for improving mobility in people with Parkinson's disease and multiple sclerosis: A systematic review and meta-analysis. Physiotherapy 2019, 105, 174-186. [CrossRef] [PubMed]

45. Kalron, A.; Givon, U. Gait characteristics according to pyramidal, sensory, and cerebellar EDSS subcategories in people with multiple sclerosis. J. Neurol. 2016, 263, 1796-1801. [CrossRef]

46. Chung, L.H.; Remelius, J.G.; Van Emmerik, R.E.A.; Kent-Braun, J.A. Leg power asymmetry and postural control in women with multiple sclerosis. Med. Sci. Sports Exerc. 2008, 40, 1717-1724. [CrossRef] [PubMed]

47. Sosnoff, J.J.; Socie, M.J.; Boes, M.K.; Sandroff, B.M.; Pula, J.H.; Suh, Y.; Weikert, M.; Balantrapu, S.; Morrison, S.; Motl, R.W. Mobility, Balance and Falls in Persons with Multiple Sclerosis. PLoS ONE 2011, 6, e28021. [CrossRef]

48. Cattaneo, D.; Jonsdottir, J. Sensory impairments in quiet standing in subjects with multiple sclerosis. Mult. Scler. 2009, 15, 59-67. [CrossRef] [PubMed]

49. Van Emmerik, R.E.; Remelius, J.G.; Johnson, M.B.; Chung, L.H.; Kent-Braun, J.A. Postural control in women with multiple sclerosis: Effects of task, vision and symptomatic fatigue. Gait Posture 2010, 32, 608-614. [CrossRef] [PubMed]

50. Kalron, A.; Givon, U.; Frid, L.; Dolev, M.; Achiron, A. Static Posturography and Falls According to Pyramidal, Sensory and Cerebellar Functional Systems in People with Multiple Sclerosis. PLoS ONE 2016, 11, e016446. [CrossRef] 